\title{
ARTIKELEN
}

\section{Introductie bij het themanummer: een drieluik van groeiende woonongelijkheid}

\author{
Cody Hochstenbach \& Nanke Verloo*
}

\section{Introductie}

De beroemde geograaf David Harvey omschreef in zijn meesterwerk Social Justice and the City uit 1973 de woningmarkt als een theater. ${ }^{1}$ De mensen met het meeste geld kunnen de beste plekken in het theater bemachtigen: de dure stoelen op de eerste rijen. Voor degenen met een smalle beurs blijven de goedkoopste stoelen in de nok over, en voor de allerlaagste inkomens is helemaal geen plek. Wellicht kun je het theater uitbreiden zodat er meer plekken beschikbaar komen, of je kunt de ticketprijzen verhogen totdat er nauwelijks nog goedkope stoelen over zijn. Nationale hervormingen op de Nederlandse woningmarkt zorgen in de grote steden voor dat laatste: door sociale huurwoningen te verkopen en te slopen blijven er minder betaalbare plekken over, waardoor een stoelendans ontstaat onder huishoudens met een laag tot middeninkomen.

De metafoor van een theater past niet alleen bij de veranderingen in de woningmarkt, maar ook bij het alledaagse leven in de stad. Al in 1937 beschreef stadssocioloog Lewis Mumford de stad als een theater van sociale interacties (Mumford in LeGates \& Stout, 2011, 93). De stad als een theater biedt ons de mogelijkheid om te onderzoeken hoe de werelden van beleid, kunst, commercie en gemeenschap met elkaar in contact komen, elkaar beïnvloeden en hoe de stad ontstaat als een product van deze interacties. Het geeft een gelaagd beeld van wat er gebeurt wanneer het beleid van het theater zelf verandert en daarmee beïnvloedt voor wie er plek is in het theater, maar ook welke voorstelling wordt opgevoerd en hoe de acteurs op het podium met elkaar samenwerken.

In dit themanummer bieden wij daarom een drieluik over de ontwikkelingen op de Nederlandse woningmarkt en de verschillende vormen van ruimtelijke en sociale ongelijkheid ten gevolge van die veranderende woningmarkt. We introduceren ons drieluik door eerst de veranderingen op de Nederlandse huur- en koopmarkt te bespreken als 'algemene trends van ongelijkheid' waarbij de woningmarkt sociale ongelijkheden in toenemende mate versterkt in plaats van dempt. Het wegdrukken of marginaliseren van sommige bevolkingsgroepen, en het tegelijkertijd ruimte bieden aan anderen, versterkt de 'ruimtelijke ongelijkheid', maar ook de 'alledaagse ervaring van ongelijkheid'. Het eerste artikel in het drieluik brengt ons naar de Rotterdamse Zuidwijk, waar André Ouwehand de gevol-

* Dr. Cody Hochstenbach is secretaris van de redactie van Beleid en Maatschappij. Dr. Nanke Verloo is lid van de redactie van Beleid en Maatschappij. 
gen van herstructurering beschrijft. Het tweede schouwspel vindt plaats in Geuzenveld, waar Saskia Welschen en Lex Veldboer onderzoeken hoe de groeiende concentratie van armoede en sociale problematiek in perifere stadswijken een complexe opgave is voor welzijnsprofessionals die met minder middelen meer moeten bereiken.Het derde stuk, van Linda van de Kamp en Saskia Welschen, speelt zich af in Amsterdam-Noord, waar zij de afbreuk van sociale cohesie onderzoeken in het alledaagse leven van een gentrificerende wijk. Tot slot beargumenteren Jan de Vries en Rina Beers in De Blinde Vlek dat het toenemende aantal dak- en thuislozen veel meer aandacht behoeft.

\section{Algemene trends van woonongelijkheid}

De Nederlandse volkshuisvesting kent een rijke traditie, en de sociale huursector blijft ten opzichte van de meeste andere landen relatief groot. Ongeveer 29 procent van de Nederlandse woningvoorraad is per 2018 in handen van woningcorporaties (CBS, 2019a). Toch staat de Nederlandse volkshuisvestingstraditie onder druk. Uitbreiding van het aandeel marktwoningen staat centraal, en de sociale huursector wordt omgevormd van een brede voorziening - voor een aanzienlijk deel van de bevolking - naar een laatste redmiddel voor wie zich niet staande weet te houden op de markt (Musterd, 2014; Hochstenbach \& Van Gent, 2018). Zo vond Stef Blok als minister van Wonen in het kabinet-Rutte 2 (2012-2017) dat woningcorporaties hun grotere en duurdere woningen moesten verkopen, zodat er een sector over zou blijven van overwegend kleine en sobere woningen. Nog steeds moedigt de Nederlandse overheid beleggers uit binnen- en buitenland aan corporatiewoningen van goede kwaliteit op te kopen, om deze vervolgens in de duurdere vrije sector te verhuren (zie bijvoorbeeld Hendriks, 2018).

Een reeks recente beleidsmaatregelen voorziet in het beperken van de Nederlandse corporatiesector (Boelhouwer \& Priemus, 2014; Hoekstra, 2017; Hochstenbach \& Van Gent, 2018). De Rijksoverheid heeft onder druk van de EU, nadat daar klachten waren binnengekomen van institutionele beleggers over oneerlijke concurrentie, in 2011 een strenge maximale inkomensgrens voor sociale huur bepaald. Bijna alle sociale huurwoningen moeten sindsdien verhuurd worden aan huishoudens met een bruto jaarinkomen tot $€ 38.035 .^{2}$ Minder huishoudens komen hierdoor nog in aanmerking voor een sociale huurwoning. Daarnaast heeft het Rijk enkele lastenverzwaringen voor woningcorporaties doorgevoerd, waaronder de verhuurderheffing uit 2013, die de corporaties inmiddels jaarlijks zo'n 1,7 miljard euro kost. De financiële mogelijkheden van corporaties lopen terug, met onder meer de verkoop van corporatiebezit en een forse vermindering van de nieuwbouw als gevolg. Daarbovenop is in 2015 de nieuwe Woningwet in werking getreden. Deze wet beperkt het speelveld van de woningcorporaties tot hun veronderstelde kerntaak: het huisvesten van de laagste inkomens. De maatschappelijke steun voor woningcorporaties heeft de afgelopen jaren bovendien een forse dreun opgelopen door een reeks misstanden. In het oog springende voorbeelden zijn derivatenspeculatie door Vestia met een miljardenstrop als gevolg, honderden miljoenen euro's verlies bij de aankoop van het voormalige 
cruiseschip de SS Rotterdam door Woonbron, en zelfverrijking door bestuurders. Beperkende maatregelen zijn weliswaar ten dele een reactie op deze misstanden, maar zeker niet uitsluitend: ze passen bovenal bij een langere beleidslijn, eind jaren tachtig ingezet, gericht op het bevorderen van de markt en het terugdringen van corporaties.

Het gevolg van dit woonbeleid is dat de sociale huursector achterblijft. Tussen 2007 en 2017 kromp de Nederlandse corporatievoorraad licht, terwijl het aantal huishoudens met 8 procent toenam. Het aandeel corporatiewoningen met een maandhuur tot $€ 720$ kromp met zo'n 5 procent. In grote steden als Amsterdam en Rotterdam liep de corporatievoorraad zelfs flink terug: in beide steden kromp de corporatievoorraad tussen 2002 en 2018 met zo'n 30.000 woningen. Bewoners van sociale huurwoningen hebben bovendien steeds vaker een laag inkomen. In 1990 had 12 procent van de sociale huurders een laag inkomen, in 2015 was dat opgelopen tot 45 procent (SCP, 2017). De woonlasten onder huurders zijn tegelijkertijd scherp toegenomen, evenals de betaalrisico's: in 2002 had 5 procent van alle huurders moeite de maandelijkse huur op te hoesten, in 2009 was dat al 9 procent, en in 2015 zelfs 18 procent. Onder woningeigenaren zijn die betaalrisico's over die hele periode stabiel gebleven rond de 2 procent (PBL, 2016).

Het aandeel koopwoningen is de afgelopen decennia aanzienlijk uitgebreid, maar stabiliseert de afgelopen jaren rond de 56 procent. Uitbreiding van het eigenwoningbezit heeft meer mensen in staat gesteld een woning te kopen en daar vermogen mee op te bouwen door langdurige prijsstijgingen op de koopwoningmarkt. Diezelfde prijsstijgingen maken het nu echter in toenemende mate lastig de koopwoningmarkt te betreden, zeker voor jongere aspirant-koopstarters, die geen overwaarde hebben om mee te nemen.

Niet alleen stijgende woningprijzen maken het lastiger een eigen woning te kopen. In reactie op de diepe financiële en huizencrisis van 2008 zijn strengere hypotheekeisen ingevoerd. Maximale leenbedragen zijn verlaagd en persoonlijke eisen verscherpt. Op de arbeidsmarkt is tegelijkertijd sprake van flexibilisering: Nederland kent relatief veel werknemers op tijdelijke contracten, en deze tijdelijkheid doet de kansen op een hypotheek slinken. Op populaire plekken, waaronder de grote steden, zijn een dubbel inkomen, vaste contracten en voldoende eigen vermogen cruciaal om een woning te kunnen kopen (zie ook Forrest \& Hirayama, 2015). Vooral voor jongvolwassenen is het lastig aan deze voorwaarden te voldoen, tenzij je kunt vertrouwen op ouderlijke financiële steun (Hochstenbach, 2018). Een gevolg is dat het aandeel kopers onder jongvolwassenen is afgenomen - zij huren daarentegen vaker in de private sector, waar de gemiddelde woonlasten erg hoog zijn (CBS, 2019b), of blijven noodgedwongen in het ouderlijk huis wonen (Lennartz, Arundel \& Ronald, 2016).

Een aanvullende factor die het lastiger maakt om te kopen is de recente toename van beleggers op de woningmarkt. Vooral kleinere particuliere beleggers mengen zich op de koopwoningmarkt, waar zij woningen opkopen om te verhuren. De opmars van dergelijke beleggers is eerder uitvoerig behandeld in een dossier in Beleid en Maatschappij, nummer 2018/3. Hoewel hier sprake is van een landelijke trend, zijn de beleggers vooral actief in de grote steden en studentensteden, en kopen zij vooral kleinere appartementen op. Deze beleggersactiviteit verdrukt 
reguliere woningzoekenden, jongere koopstarters in het bijzonder (Bosma e.a., 2018).

De combinatie van het beperken van de sociale huursector en het ontoegankelijker worden van de koopmarkt - eigenlijk het tegelijkertijd wegnemen én duurder maken van stoelen in het theater - betekent dat een groeiende groep huishoudens tussen wal en schip valt. Het gaat dan om middeninkomens en jonge starters die niet (meer) in aanmerking komen voor sociale huur en tegelijkertijd niet in staat zijn een woning te kopen. Het aanpakken van de benarde positie van middeninkomens op de woningmarkt, vooral in de steden, is inmiddels tot beleidsprioriteit verheven. Politici en beleidsmakers schuiven de particuliere huursector naar voren als oplossing. Grote investeerders en particuliere beleggers zouden kunnen voorzien in de vraag naar vrije huurwoningen waarvoor geen wachttijden of maximale inkomensgrenzen gelden, is de gedachte. Vooral het realiseren van zogenaamde middenhuurwoningen - met maandhuren tussen de $€ 720$ en $€ 1000$ - zijn verheven tot beleidsprioriteit op lokaal en nationaal niveau. In hun bijdrage in dit nummer (De Blinde Vlek) benadrukken Jan de Vries en Rina Beers echter dat de grootste problemen zich voordoen helemaal aan de onderkant van de woningmarkt, waar het aantal dak- en thuislozen de afgelopen jaren scherp is toegenomen. Deze schrijnende problematiek krijgt echter nauwelijks aandacht, laat staan dat er gecoördineerd en toereikend beleid op gevoerd wordt.

\section{Ruimtelijke ongelijkheid}

Bovenstaande trends duiden op toenemende verschillen op de woningmarkt. De correlatie tussen iemands sociaaleconomische positie en haar of zijn woonsituatie is de afgelopen jaren versterkt. Sociale huurders hebben steeds vaker een laag inkomen, terwijl kopers vaker over een hoog inkomen en eigen vermogen beschikken. De groeiende particuliere huursector huist een diverse bevolking, waaronder veel middeninkomens en jongvolwassenen. Ongelijkheden op de woningmarkt nemen toe, waarbij sociale én particuliere huurders een groter deel van hun inkomen zijn gaan betalen aan woonlasten, en kopers juist een relatief kleiner deel.

Dit zorgt voor sterkere ruimtelijke concentraties. Buurten met veel sociale huur zien toenemende armoedeconcentraties en kampen met neergang. De buurten met de goedkoopste huurwoningen kennen een toenemende opeenstapeling van problematiek door een toegenomen instroom van zwakke en hulpbehoevende huishoudens. Ruimtelijke segregatie tussen arm en rijk is de afgelopen jaren toegenomen in de meeste Europese steden (Tammaru e.a., 2016). Ook in de grote Nederlandse steden zijn deze ruimtelijke scheidslijnen de afgelopen jaren gegroeid (Van Gent \& Hochstenbach, 2019). Een terugkerend patroon hierbij is dat rijke huishoudens doorgaans het sterkst gesegregeerd wonen. Huishoudens met de hoogste inkomens kunnen het zich veroorloven te wonen in woonwijken waar haast geen armere gezinnen wonen. Dit kan betekenen dat zij zelden met 
andere groepen in contact komen in de openbare ruimte en in publieke functies zoals scholen, de supermarkt of de huisarts.

Ruimtelijke ongelijkheid is veel meer dan segregatie. In de meeste grote steden heeft gentrificatie, de opwaardering van voorheen arme stadswijken, zich ontwikkeld tot een veelvoorkomend proces (Hackworth \& Smith, 2001). Gentrificatie is niet langer beperkt tot een handjevol buurten, maar breidt zich als een olievlek uit. Deze gentrificatie zorgt in eerste instantie voor meer sociale menging; mensen met een wat hoger inkomen vestigen zich immers in een overwegend arme buurt. Gaat dit proces door, dan wordt een kantelpunt bereikt en zorgt verdere gentrificatie voor ontmenging. Gentrificatie in Nederlandse steden betekent de uitsluiting van lagere inkomens: voor hen blijft minder plek in deze buurten. De gentrificatie zet een suburbanisatie van armoede in gang, waarbij lagere inkomens de stad uit worden gedrukt (Hochstenbach \& Musterd, 2018). Andere lage inkomens blijven als gevolg juist zitten waar ze zitten door een gebrek aan alternatieven op de woningmarkt. Niet alleen de bevolkingssamenstelling van de buurten verandert, maar bijvoorbeeld ook lokale voorzieningen: de oude bruine kroeg of de Turkse groenteboer moet plaatsmaken voor de dure koffiezaak of micro brewery. Al deze veranderingen beïnvloeden de ervaringen van de oorspronkelijke bewoners. Sommigen waarderen de veranderingen, maar anderen ervaren buurtverlies met het verdwijnen van oude netwerken en ankerpunten.

Nederlands stedelijk beleid heeft een lange traditie van het tegengaan van concentraties van armoedegroepen of minderheden middels sociaal mengingsbeleid. De grondgedachte is dat dergelijke concentraties een negatieve invloed kunnen uitoefenen op de levenskansen van bewoners, en buurten bovendien moeilijker 'beheersbaar' maken (Uitermark, 2003; Musterd \& Andersson, 2005). Mengingsbeleid kenmerkt zich doorgaans door integrale herstructurering van de woningvoorraad, waarbij goedkope huurwoningen worden gesloopt en vervangen door duurdere marktwoningen. De effecten van dit beleid zijn wisselend: het draagt weliswaar bij aan buurtmenging, maar heeft nauwelijks effect op individuele levenskansen. In zijn bijdrage in dit nummer behandelt André Ouwehand de herstructurering van Zuidwijk in Rotterdam, een typisch voorbeeld van stedelijke herstructurering. Op basis van uitvoerig kwalitatief onderzoek laat hij zien dat bewoners deze fysieke herstructurering doorgaans waarderen. Tegelijkertijd past het beleid binnen bredere beleidslijnen die zijn gericht op het inkrimpen van de sociale woningvoorraad. Lagere inkomensgroepen betalen zo de prijs voor sociale menging in de vorm van afgenomen woonkansen (zie ook Hochstenbach, 2019).

\section{Alledaagse ervaringen van ongelijkheid}

Als we de stad als theater zien, zorgt ruimtelijke ongelijkheid ervoor dat armoede zich steeds meer concentreert op bepaalde plekken - mensen hebben niet de mogelijkheid om een stoel (lees: woning) op een goede plek in het theater (lees: stad) te kopen of huren. Tegelijkertijd is het alledaagse leven op die plekken steeds vaker een eenzijdige voorstelling. In armere wijken spelen de scènes zich af tussen professionals die met minder middelen hulp moeten bieden aan een 
groeiende groep bewoners met een complexe stapeling van financiële en sociale problematiek. Daartegenover staan de scènes van wijken die door sociaal mengingsbeleid steeds sneller gentrificeren en waar oorspronkelijke bewoners zich steeds minder thuis voelen op straat, in de winkels en zelfs in de activiteiten in het buurthuis. In die alledaagse plekken wordt zichtbaar wat voor gevolgen de veranderde woningmarkt heeft op het niveau van de buurt.

Saskia Welschen en Lex Veldboer laten in hun artikel zien dat ruimtelijke uitsortering leidt tot de concentratie van armoede en sociale problematiek in de perifere wijken van de stad. Dit heeft grote gevolgen voor de opgave van sociaal werk. In wijken waar de zogenaamde residualisering duidelijk neerslaat in de vorm van toenemende concentraties van armoede en verschillende soorten sociale problematiek, neemt de zorgvraag voor professionals in het welzijnswerk toe. Daarnaast observeren zij dat de transitie naar een participatiesamenleving ervoor zorgt dat veel van de zorgtaken op de schouders van de gemeenschap komen te liggen. Welzijnsprofessionals hebben vaker de taak om verbindingen te leggen en plekken voor ontmoeting te creëren in plaats van zorgtaken uit te voeren. Met andere woorden, de opgave verandert, waardoor er nieuwe vaardigheden worden gevraagd van professionals, die in steeds complexere omstandigheden met minder middelen veel meer moeten doen.

De noodzaak tot het leggen van nieuwe horizontale verbindingen tussen bewoners is een terugkomend thema dat een direct gevolg lijkt te zijn van ruimtelijke uitsortering en de veranderende stad. In het artikel van Linda van de Kamp en Saskia Welschen wordt heel gedetailleerd zichtbaar hoe dat gebrek aan thuis voelen zich manifesteert in de woonwijk. Dit heeft zijn grondslag in processen van sociaal mengbeleid en toenemende gentrificatie. Ondanks dat er wordt verwacht dat sociaal mengen een emancipatoire werking heeft, blijkt uit hun langdurige etnografische studie in Amsterdam-Noord dat sociale cohesie juist vermindert door het beleid van mengen. In de veranderde wijk herkenden oorspronkelijke bewoners hun buren niet langer en gingen de activiteiten zoals bingo verloren nadat er enkel nog subsidie werd verstrekt aan pedagogisch verantwoorde activiteiten die oude en nieuwe bewoners zouden moeten verbinden.

Gemeenschappen en het gevoel ergens thuis te zijn worden niet alleen gevormd door samen actief dingen te doen - zoals participatiebeleid eist en waar subsidieverstrekking veelal op ingericht is. Het gevoel van thuis ontwikkelt zich ook door hele alledaagse interactie en herkenningen op straat, in de winkel of door alledaagse activiteiten in het buurthuis. Deze zogenaamde 'publieke familiariteit' (Blondeel, 2006) gaat over het bevestigende knikje van de bakker, de goedemorgen van je buurman en het snelle kopje koffie in het buurthuis. Het zijn die kleine dingen die ons het gevoel geven ergens thuis te horen, elkaar te kunnen vertrouwen en veilig te zijn, zonder dat we elkaar echt persoonlijk hoeven te kennen. Het artikel van Van de Kamp en Welschen laat zien dat gentrificatie ervoor kan zorgen dat bewoners een stuk minder publieke familiariteit ervaren en zich zorgen maken over het onderlinge vertrouwen in de buurt.

Publieke familiariteit groeit langzaam, maar kan heel snel worden afgebroken. De snelle verandering in stadswijken heeft op veel plekken afbreuk gedaan aan die alledaagse herkenning van elkaar. Dat betekent echter niet dat publieke familiari- 
teit tussen oude en nieuwe bewoners nooit kan ontstaan. Het zal alleen wederom een lang en gestaag proces van alledaagse interacties en herkenningen zijn om dat op te bouwen. Om dit proces te stimuleren zijn laagdrempelige ontmoetingsplekken cruciaal. Lokale overheden zouden moeten inzetten op het ondersteunen van diverse activiteiten in het buurthuis, niet alleen activiteiten met een zogenaamde culturele, artistieke of pedagogische onderbouwingen, maar ook bingo en kaartclubs en andere activiteiten waar een grote groep mensen behoefte aan heeft. Ten tweede moeten we blijvend investeren in goede publieke ruimtes en deze onderhouden - van simpele straatbankjes tot schone speeltuinen en parken. Ten derde groeit publieke familiariteit door de ontmoeting bij de bakker of slager en andere alledaagse functies. Lokale overheden kunnen zorg dragen voor deze functies, zodat ze blijven bestaan en niet worden overgenomen door lucratievere ondernemingen die hogere huurprijzen kunnen betalen.

Burgers ervaren termen als 'ongelijkheid' of 'uitsluiting' niet in abstracte processen, maar tijdens alledaagse plekken en interacties (Piven \& Cloward, 1977; Verloo, 2017). Wanneer jouw activiteit niet langer mag plaatsvinden in het buurthuis omdat het niet aan de subsidienorm voldoet, wanneer jij de meeste winkels niet in gaat omdat je het simpelweg niet kunt betalen, of wanneer de welzijnswerker geen tijd heeft om een-op-een met je te praten door een te hoge caseload in de wijk, ondervind je aan den lijve wat het betekent om in een arme of juist gegentrificeerde wijk te wonen. Het is echter op diezelfde lokale plek, in de interacties met beleidsmakers en elkaar, dat publieke familiariteit kan groeien en wijken inclusiever kunnen worden. Ten eerste moet er structureel gekeken worden naar de woningmarkt; hoe kunnen we de groeiende ruimtelijke ongelijkheid tegengaan? Het gaat dan onder andere om eigendomsverhoudingen op de woningmarkt, toegangsregels - wie kan aanspraak maken op welke woning? - en de ruimtelijke spreiding van verschillende woonsegmenten. Maar daarna kunnen we ook lokaal dingen doen. Door alledaagse ontmoetingen tussen buren te ondersteunen en niet te hoge verwachtingen te hebben van de emancipatoire werking van mengen kan de ervaring van 'uitsluiting' op lokaal niveau weer een ervaring worden van erbij te horen.

\section{Noten}

1 Op p. 168, dank aan Michiel van Meeteren voor het attenderen op dit citaat.

2 Deze inkomensgrens verandert jaarlijks. Dit is de grens voor 2019.

\section{Literatuur}

Blondeel, P. (2006). 'Als het werkt, komt de samenhang vanzelf. Hoe burgers omgaan met wat niet verandert en wat steden kunnen. Den Haag: R4R.

Boelhouwer, P., \& Priemus, H. (2014). Demise of the Dutch social housing tradition: impact of budget cuts and political changes. Journal of Housing and the Built Environment, 29 (2): 221-235. 
Bosma, J., Hochstenbach, C., Fernandez, R., \& Aalbers, M. (2018). De politiek van buy-tolet. Beleid en Maatschappij, 45 (3): 288-298.

CBS (2019a). Voorraad woningen; eigendom, type verhuurder, bewoning, regio. Den Haag: Centraal Bureau voor de Statistiek.

CBS (2019b). Woonlasten huishoudens; kenmerken huishouden, woning. Den Haag: Centraal Bureau voor de Statistiek.

Forrest, R., \& Hirayama, Y. (2015). The financialisation of the social project: Embedded liberalism, neoliberalism and home ownership. Urban Studies, 52 (2): 233-244.

Gent, W. van, \& Hochstenbach, C. (2019). The impact of gentrification on social and ethnic segregation. In: S. Musterd (red.), Handbook on Urban Segregation. Cheltenham: Edward Elgar.

Hackworth, J., \& Smith, N. (2001). The changing state of gentrification. Tijdschrift voor economische en sociale geografie, 92 (4), 464-477.

Harvey, D. (1973). Social Justice and the City. Cambridge, MA: Blackwell Publishers.

Hendriks, P. (2018). Hoe word je rijk met sociale woningen? De overheid legt het buitenlandse beleggers uit. Follow the Money. www.ftm.nl/artikelen/buitenlandse-beleggerscorporatiewoningen?share $=1$, geraadpleegd op 7 augustus 2019 .

Hochstenbach, C. (2018). Spatializing the intergenerational transmission of inequalities: Parental wealth, residential segregation, and urban inequality. Environment and Planning A: Economy and Space, 50 (3): 689-708.

Hochstenbach, C. (2019). Sociale menging? Vergeet de elitewijken niet! Beleid en Maatschappij, 46 (1): 204-206.

Hochstenbach, C., \& Gent, W. van (2018). Betaalbaar wonen verder weggedrukt: de sociale en ruimtelijke implicaties van de Woningwet 2015. Essay geschreven voor de evaluatie van de Woningwet 2015 door de Commissie Van Bochove, in opdracht van Aedes.

Hochstenbach, C., \& Musterd, S. (2018). Gentrification and the suburbanization of poverty: Changing urban geographies through boom and bust periods. Urban Geography, 39 (1): 26-53.

Hoekstra, J. (2017). Reregulation and Residualization in Dutch social Housing: a critical Evaluation of new Policies. Critical Housing Analysis, 4 (1): 31-39.

LeGates, R.T., \& Stout, F. (red.) (2011). The city reader. New York: Routledge.

Lennartz, C., Arundel, R., \& Ronald, R. (2016). Younger adults and homeownership in Europe through the global financial crisis. Population, Space and Place, 22 (8): 823-835.

Musterd, S. (2014). Public housing for whom? Experiences in an era of mature neo-liberalism: The Netherlands and Amsterdam. Housing Studies, 29 (4): 467-484.

Musterd, S., \& Andersson, R. (2005). Housing mix, social mix, and social opportunities. Urban Affairs Review, 40 (6): 761-790.

PBL (2016). Betaalrisico's in de huur- en koopsector, 2002-2015. PBL: Compendium voor de Leefomgeving.

Piven, F.F., \& Cloward, R.A. (1977). Poor people's movements: Why they succeed, how they fail. New York: Pantheon.

SCP (2017). Sociale Staat van Nederland 2017. Den Haag: Sociaal en Cultureel Planbureau.

Tammaru, T., Marcińczak, S., Ham, M. van, \& Musterd, S. (2016). Socio-Economic Segregation in European Capital Cities: East Meets West. New York/Londen: Routledge.

Uitermark, J. (2003). 'Social mixing' and the management of disadvantaged neighbourhoods: The Dutch policy of urban restructuring revisited. Urban Studies, 40 (3), 531-549.

Verloo, N. (2017). Learning from informality? Rethinking the mismatch between formal policy Strategies and informal tactics of citizenschip. Current Sociology, 65 (2): 167-181. 